\title{
Harriaren egituraren zenbakizko eredua artezketan
}

\author{
(Numerical model of the grinding wheel)
}

\author{
Juan Luis Osa ${ }^{1 *}$, Ana Boyano ${ }^{2}$,Borja Fernandez-Gauna ${ }^{3}$, \\ Mikel Larrañaga ${ }^{4}$ \\ ${ }^{1}$ Ingeniaritza Mekanikoa Saila, \\ Euskal Herriko Unibertsitatea UPV/EHU, Eibar \\ 2 Ingeniaritza Mekanikoa Saila, \\ Euskal Herriko Unibertsitatea UPV/EHU, Vitoria-Gasteiz \\ ${ }^{3}$ Adimen Konputazionala Taldea, Hizkuntza eta Sistema Informatikoak Saila, \\ Euskal Herriko Unibertsitatea UPV/EHU, Vitoria-Gasteiz \\ ${ }^{4}$ GALAN Taldea, Hizkuntza eta Sistema Informatikoak Saila, \\ Euskal Herriko Unibertsitatea UPV/EHU, Vitoria-Gasteiz \\ *j.osa@ehu.eus
}

DOI: $10.1387 /$ ekaia.17880

Laburpena: Harriaren portaera artezketa eragiketan, hein handi batean, bere egitura granularraren naturatik datorkio. Gaur egungo harriak aglomeratzaileak batzen dituen ale urratzaile gogorrez osatutako diseinuzko konglomeratu porotsuak dira. Alearen ezaugarriek, aglomeratzailearen erresistentziak eta, poroekin batera, hiruren arteko proportzioak harriaren izaera baldintzatzen dute. Ekoizpen prozesua erdi-sekretua izan ohi da, ekoizlearen urteetako esperientziaren emaitza. Harriaren propietate mekanikoak, diseinuzko material izaki, aurrez ezagutu ahal izan beharko lirateke. Hala ere, bere natura heterogeneo konplexuak modelizazioa zailtzen du. Berriki, elementu diskretuen metodoa aplikatu da harriaren portaera simulatzeko. Lan honetan eredua eraikitzeko prozedura berria aurkezten da. Lanak propietate mekanikoen homogeneizazio prozesua ere azaltzen du.

Hitz gakoak: Artezketa, elementu diskretuen metodoa, harria, homogeneizazioa.

Abstract: The behaviour of the wheel when grinding stems in a way from the nature of its granular structure. Current grinding wheels are porous conglomerates of hard abrasive grains bonded by the formed by the binder. The characteristics of the abrasive grits, the resistance of the bonding material, together with the porous network, determines wheel's performance. The know how of wheel manufacturers is kept zealously 
in secret. The mechanical properties of the wheel, as an engineered material, should be able to be predicted in advance. However, its complex heterogeneous nature hinders the modelling. Recently, the discrete element method has been successfully applied in the modelling of the grinding wheel. This paper describes the proper creation procedure of the model. The work includes the calibration procedure of mechanical properties due to homogenisation.

Keywords: Grinding, discrete element method, grinding wheel, homogenisation.

\section{SARRERA}

Gure aiton-amonek aizkorak eta erremintak zorrozteko erabiltzen zuten harria gaur egun elementu mekanikoen fabrikazioan ezinbesteko eragiketa bihurtu da. Harri horren eraldaketaren arrakasta, material gogorretan gainazal-akabera eta doitasun bikainak lortzeko duen gaitasuna izan da. Eskakizun tekniko zorrotzak dituzten elementu mekanikoetan erabiltzen denez, artezketa balio erantsi handiko eragiketa da.

Gaur egungo harriak diseinuzko konglomeratu artifizialak dira. Ale urratzaile gogorrak txirbil-harroketaz arduratzen dira eta hauskorragoa den aglomeratzaileak eusten ditu aleak eta tarteetan poroak eratu. Harriaren morfologia granularrak eta propietate mekanikoek eragin zuzena dute arteztean. Hasteko, harriaren gainazalaren topografian eragiten du, piezaren gainazalerekin interakzio zuzena baitauka materiala harrotzean. Harriaren gainazala diamantaketa bidez prestatzen da. Harriaren $d_{\mathrm{g}}$ ale-neurriak eta $V_{\mathrm{g}}$ urratzaile frakzio bolumetrikoak diamantaketan gainazaleko aleen eskuragarritasunean eragiten dute. Era berean, $d_{\mathrm{g}}, V_{\mathrm{g}}$ eta aglomeratzailearen erresistentziak harriaren gradua edo gogortasuna, hau da, gainazaleko ale bat harritik askatzeko erresistentzia finkatzen dute. Urratzaile-aglomeratzaile bikoteak osatutako solidoak duen zurruntasunak, artezketa-indarren pean harria deformatu eta kontaktu-baldintzak aldatzen ditu. Horrek, besteak beste, bero-fluxuan (kalte termikoa) eta aleen higaduran eragiten du. Beraz, nabarmena da harriaren osaketaren eragina artezketan. Izatez, aplikazio bakoitzak dauka bere harri mota egokia. Interesgarria izango litzateke, osagaien konbinazio jakin batentzat, harriaren propietateak aurreikusten dituen eredua izatea.

Azken hamarkadetan artezketaren zenbakizko ereduen garapena oso aktibo egon da, prozesuaren optimizazioak dakartzan onurak bultzatuta $[1,2,3]$. Harria solido ez-jarraitu heterogeneoa da. Ondorioz, bere portaera mekanikoa deskribatzeko ingurumen jarraituen mekanikako ohiko zenbakizko erreminten eta hurbilpen analitikoen erabilera zailtzen da. Azken urteetan geotekniarako garatu zen elementu diskretuen metodoa (discrete element method, DEM) artezketaren simulazioan indartsu sartu da eta eremu granularrak deskribatzeko duen potentziala profitatu du $[4,5,6]$. 
Lan honek harriaren egitura granularraren zenbakizko eredua DEM bidez aurkezten du. Ereduak harriaren ezaugarri morfologikoak eta propietate mekanikoak aurreikustea du helburu. Lehenik eta behin, harriak dituen ezaugarri morfologikoak eta propietate mekanikoak deskribatuko dira. Ondoren, argitaratu diren zenbakizko ereduen berrikuspena gehituko da. Azkenik, harriaren egitura DEM eredu bidez eraikitzeko metodologia berria aurkezten da. Lana propietate mekanikoen aurrekalibrazio prozedurarekin amaitzen da. Garatutako eredua beiraztatutako alumina ohiko harrietara mugatu da.

\section{HARRIA ETA HARRIAREN ZENBAKIZKO EREDUAK}

Urratzaile-aglomeratzaile konbinaketa anitzek aplikazio jakin batentzat soluzio egokia existitzea ahalbidetzen dute. Atal honetan harrien osaketaz gain, proposatu diren zenbakizko ereduak deskribatzen dira.

\subsection{Harriaren ezaugarriak}

Harriaren egitura hauskorra bere fabrikazioaren ondorio da (1(a) Ir.): urratzaile-aglomeratzaile nahasketa, trinkotzea eta labealdia. Harriaren osaketa ezagutzea ezinbestezkoa da haren eredua eraikitzeko. Bestalde, harriaren osaketa irekia da: harri ekoizleak izendapen berdinaren pean bi harrialdaera izan ditzake eta osagaiak, proportzioak eta prozedurak sekretuan gorde. Graduak edo gogortasunak (alea harritik askatzeko erresistentzia) harriaren zurruntasuna zeharka definitzen du eta zuzenki eragiten du harriaren portaeran. Harriaren zenbakizko DEM ereduak hori guztia modelatzeko gai izan behar du.

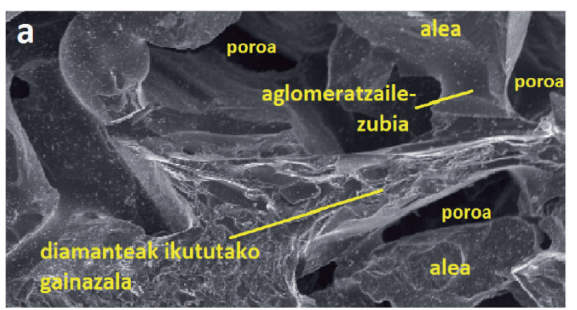

b

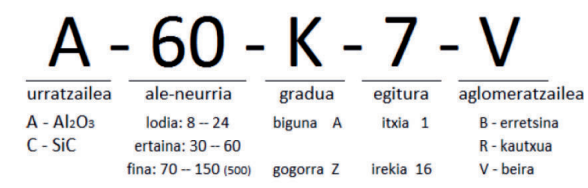

1. irudia. (a) A60K7V harriaren behaketa ekortze mikroskopio elektroniko (scanning electron microscope; SEM) bidez: ale urratzaileak; aglomeratzaile-zubia eta poroak; (b) ohiko harrien izendapena.

Harrien izendapena nazio eta nazioarteko erakundeek adostutako arauek erregulatzen dute, besteak beste, ISO R655:1999 araua. Izendapenak harriaren osagaiak eta ezaugarri mekanikoak zehazten ditu. 1(b) Iru- 
diak harriaren izendapenaren adibidea dakar (A60K7V). Izendapenean, lehenengo hizkiak material urratzaileen familia adierazten du. Ohiko urratzaileak alumina (A) eta silizio-karburoa (C) dira. Hizkiaren eskuineko zenbakiak, galbahearen sare-zenbakia, hau da, ale-neurria adierazten du. Hurrengo hizkiak harriaren gradua edo gogortasuna adierazten du. S egitura zenbakiak $V_{\mathrm{g}}$ urratzaile frakzio bolumetrikoa definitzen du. Azken hizkiak aglomeratzailea zehazten du: (V) beiraztatua, (R) erretxina edo (M) metalikoa.

Harriaren portaera, urratzaile-aglomeratzaile ezaugarrien eta, poroekin batera, harrian duten bolumenaren kontzentrazioaren menpe dago. Harrien ekoizleek osagai bakoitzaren frakzio bolumetrikoaren $\left(V_{\mathrm{g}}\right.$ urratzaile, $V_{\mathrm{b}}$ aglomeratzaile eta $V_{\mathrm{p}}$ poro frakzioak) eta pisuaren kontrol zorrotza eramaten dute: hiruren batura bat da. Behin osagaiak nahastuta, moldean sartu eta bolumen jakin batera arte zanpatzen da, $V_{\mathrm{g}}$ doitzeko.

Osagaien arteko proportzioek muga teknologikoak dituzte, bai ekoizpenean, baita erresistentzian ere. 2(a) Irudiko grafiko trigonalean interesgarria da proportzio berdineko lerroetan aldaketak aztertzea [7]. Behin urratzailebolumena definituta, gainontzeko bolumena aglomeratzailearen eta porositatearen artean banatzen da. $V_{\mathrm{g}}$ handitu daiteke $(>\% 60)$ neurri ezberdineko aleak nahastuz; murriztu ( $<\% 30)$, berriz, poro bihurtuko diren partikula betegarriak gehituz eta aleen forma kontrolatuz. Trinkotze minimoa aleen arteko kontaktu minimoak zehazten du. Poroen neurria eta forma, ale urratzaileen neurriaren eta formaren funtzioan daude. Porositate altuak hozgarriari sarrera eman eta txirbilari irteera errazten dio arteztean. Aglomeratzaile-kopurua gehituz lotura-zubiak indartzen dira; harriaren gogortasuna handitzen da eta, era berean, porositatea murrizten da. Aglomeratzailearen jariakortasuna handituz ere, urratzailea errazago bustitzen eta estaltzen da eta gogortasuna zerbait igotzen da.
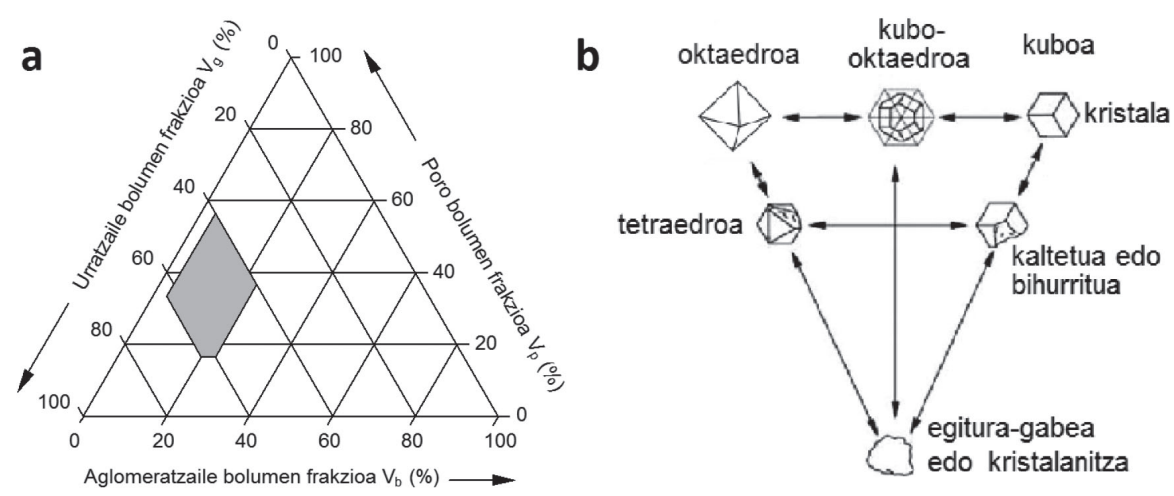

2. irudia. (a) Harrien osaketa bolumetrikoaren diagrama trigonala; eremu grisak muga teknologikoak zehazten ditu; (b) aleen geometria-aldaerak [7]. 
Harriaren egituraren zenbakizko eredua artezketan

Neurri eta mota ezberdineko aleak nahastu ahal dira harri berean. Adibidez, eraginkortasuna hobetzeko, ale txiki hauskorrak ale handi zailekin nahasten dira. Ale-neurria galbaheak duen hari-kopuruarekin zehazten da, hau da, harien arteko distantziarekin. Ondoz ondoko ale-neurrien nahasketak ohikoak dira $V_{\mathrm{g}}$ doitzeko. $d_{\mathrm{g}}$ alearen batez besteko neurria nahasketaren ehunekoen arabera erabakitzen da eta 1 ekuazioarekin estimatu daiteke [8], $M$ galbahearen sare-zenbakia izanik. Aleak nahasten ez badira, ale-neurriak banaketa uniformea du; nahasketak, berriz, banaketa normala. Harri-ekoizleak nahasketaren balio zehatzak zabaltzeko zale ez direnez, egile denek ale-nahasketa arbuiatu dute. S egitura zenbakiarekin $V_{\mathrm{g}}$ estimatu daiteke (2 ek.) [8].

$$
\begin{gathered}
d_{g}=\frac{15,2}{M} \\
V_{g}=2(32-S)
\end{gathered}
$$

Beira-aglomeratzaileak, ale urratzaileekin batera tenperatura altuetan hautsen nahasketa (beira, karea, flux kimikoak) sinterizatuz lortzen dira. Hautsak eta urratzaileak urarekin edo destrinarekin nahasten dira. Aurreformari su ematen zaio labeko ingurune kontrolatuan. Tenperatura altuek ale urratzaile eta aglomeratzailearen arteko oxidoen difusioari esker, lotura fisiko-kimiko indartsua lortzen dute. Beirak lotura-zubiak sortzen ditu, kareak aurreformari berdean erresistentzia ematen dio manipulatu ahal izateko, eta fluxek aglomeratzaileak urratzailea bustitzea edo estaltzea errazten du eta gainazal-tentsio egokia sortu.

Materiala harrotzeko gaitasuna ale urratzaileen esku dago. Harriaren gorputzak biraketa transmititzeaz gain, aleak eutsi eta artezketa-indarrak jasan behar ditu. Porositate kontrolatuak hozgarriaren xurgapena erregulatzen du. Ezaugarri horiek berariaz garatutako proben bidez neurtzen dira. Gogortasun- (Knoop eta Vickers) eta birrinkortasun-probak dira urratzaileei egiten zaizkien saiakuntza nagusiak. Aglomeratzailearen jariakortasuna tantaren probaren bidez neurtzen da, malda jakinean laginaren desplazamendua neurtuz. Harriaren gradua harriaren $E_{\mathrm{s}}$ elastikotasun moduluaz definitzen da era ez-zuzenean [9]. Erresonantzia saiakuntza gailendu da $E_{\mathrm{s}}$-ren neurketan, teknika azkarra eta ez-suntsikorra. Erresonantzia-analisiak, piezaren maiztasun naturala neurtzen du eta $E_{\mathrm{s}}$ harriaren oinarrizko makurdura-modu binodalarekin erlazionatuz kalkulatzen da. $v_{\mathrm{s}}$ Poissonen modulua ere erresonantzia-analisi bidez zehazten da, trakzio eta bihurdura bibrazio-moduak aztertuz. $v_{\mathrm{s}}$ konstantetzat har daiteke harri mota jakin batentzat tarte zabal batean [9].

Ale-geometriak harriaren fabrikazioan aleen trinkotzean edo egituraren irekitasunean eragiten du. Aluminak egitura kristalbakarra edo kristala- 
niztuna har dezake, fabrikatzean gehitutako gehigarrien eta labe-baldintzen arabera. Zapaltze-prozesuak eta kristal-egiturak aleen geometria eta eragindako kaltea definitzen dute. Aleek geometria kubiko (blocky), angeluarra (tetraedro) eta puntaduna (luzea) dute. Nahiz eta egitura eta konposizioa partekatu, geometriak alearen portaera (birrinkortasuna, zorroztasuna, higadura) aldatzen du (2(b) Ir.).

\subsection{Zenbakizko ereduak artezketan}

Elementu finituen (FEM) eta diferentzia finituen metodoak (FDM) nagusitzen dira artezketa-eredu termikoetan [2, 3]. FEM gorputz heterogeneoen portaera mekanikoa simulatzeko ere gai bada, baina harriaren egitura porotsua fidelki deskribatzeko eta materialen propietateen erlazio eratzaileak doitzeko zailtasunak dauzka. Harriaren egituraren morfologia 3D marrazketa-ereduak aurkeztu dira literaturan $[10,11,12]$. Aleen geometria eta dimentsioak parametrizatuak daude eta, astintze teknikaren bidez, uniformeki banatuak dauden elementuak ausazko posizioan eta orientazioan kokatzen dira.

Makina bat topografia-eredu garatu dira piezaren gainazaleko zimurtasuna edo artezketa-indarrak aurreikusteko [13]. Horiek, harriaren egitura granularra sortzean, ale urratzaileak astintze teknikaz kokatutako esferez ordezkatzen dira. Hala ere, horrela sortutako gorputzak zurrunak dira.

Berriki, harriaren bi DEM eredu aurkeztu dira. Li-ren taldearen ereduan $[4,5]$ oktaedro geometria duten elementu diskretuek (DE) ordezkatzen dituzte ale urratzaileak, horiek astintze bidez kokatuz eta orientatuz. Aglomeratzaile-zubien morfologia eta frakzio bolumetrikoa fidelki erreproduzitzen saiatzen dira, paraleloan antolatutako habe elastiko sare erredundantearekin (3(a) Ir.). Habeen propietate mekanikoak konpresio-probetan neurtutako erresistentziarekiko kalibratzen dituzte, elastikotasuna erabili beharrean.
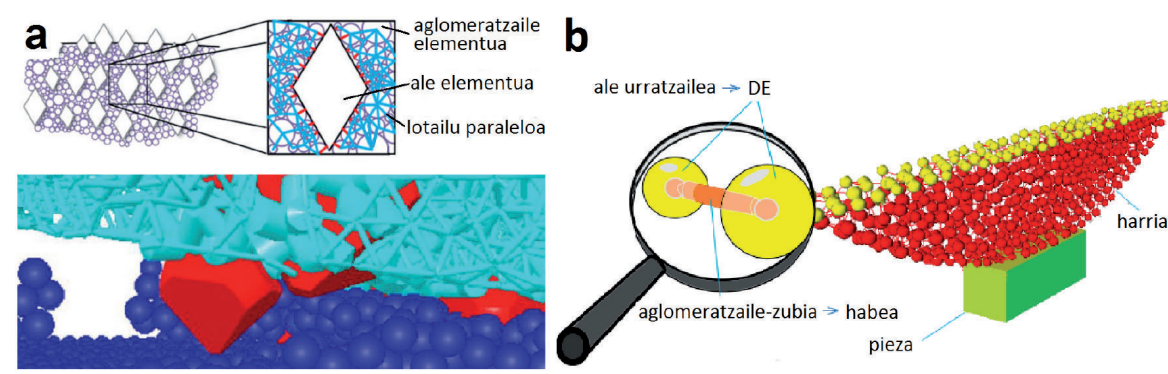

3. irudia. (a) Aglomeratzaile-zubiak geometrikoki modelatzen dituen habe-sistema paralelo erredundantea oktaedro DEen artean [4]; (b) zenbakizko sinterizazio bidez eraikitako DEM eredua: DEen diametroa murriztua dago eta habeek aglomeratzaile-zubien papera dute [6]. 
Harriaren egituraren zenbakizko eredua artezketan

Osaren taldeak 16j, urratzaile ale bakoitza DE esferikoz ordezkatzen du (3(b) Ir.). Eredua sortzeko André-k [14] garatutako zenbakizko sinterizazio prozedura moldatzen dute: elementuak ausaz kokatzen dira iteratiboki pareta elastikoak dituen eremu itxian. Kontaktuan dauden DEen artean habeak ipintzen dira aglomeratzaile-zubiak ordezkatzeko. Horien propietate mekanikoen kalibrazioa, harriaren elastikotasuna erabiltzen dute erreferentziatzat. Ale-neurria $d_{\mathrm{g}}$ eta urratzaile frakzio bolumetrikoa $V_{\mathrm{g}}$ aldi berean lortzeko, beharrezko $N_{\mathrm{DE}} \mathrm{DE}$ kopurua erreferentziatzat hartuz eredua eraiki, eta $d_{\mathrm{g}}$ murrizpen-faktore batez doitzen dute.

Bi eredu horietan, DEak ez daude kontaktuan (Lirena astintzeagatik eta Osarena murrizketagatik). Liren habeek ez dute aglomeratzailea era egokian modelatzen; Osarenean, berriz, aleko habe-kopurua beti da berdina, DEen tamaina murriztuz lortzen baita $d_{\mathrm{g}}$-ren eta $V_{\mathrm{g}}$-ren doikuntza.

\section{HARRIAREN DEM EREDUA}

Atal honetan, Osaren eredutik abiatuz, harriaren DEM eredua eraikitzeko prozedura berria deskribatzen da. Lehenik, elementu diskretuen metodoa (DEM) aurkezten da eta harriaren eredua eraikitzeko egindako moldaketak izendatzen dira. Ondoren, harriaren DEM eredua sortzeko prozedura zehazten da. Azkenik, aglomeratzaile-zubien lana egiten duten habeen propietate mekanikoen kalibrazioaren aurretiko azterketa aurkezten da.

\subsection{Elementu diskretuen metodoa}

Metodo diskretuak, partikula-kopuru handi baten mugimenduak konputatzen dituzten zenbakizko metodoak dira $[15,16]$. Dinamika molekularra (molecular dynamics, MD) eta DEM dira ezagunenak. MDak atomoen interakzioak simulatzen ditu. DEM, berriz, mikroeskalan eta mesoeskalan aplikatzen da, DEen orientazioa kontuan hartu daiteke eta, DE esferikoez gain, poliedroak ere erabili daitezke. DE batek partikula askea (hondarra, artoa...) edota bolumen-elementu adierazgarria (representative volume element, RVE) modelatu dezake. Azkenak gorputz baten izaera jarraitua modelatzen du fenomeno fisikoaren eskalaren arabera. Harriak, izaera solidoa duenez, material jarraituaren tratamendua jasoko du. Nahiz eta material heterogeneoa izan, bere portaera jarraitua azaleratzen da, ale urratzaile-aglomeratzaile-poro nahasketak bat eginda lan egitean. DEMaren ausazko naturak eremu granularretan sortzen diren indar-sareak aztertzea ahalbidetzen du. Hala ere, DEMak kostu konputazional handia dauka eta erabilpena simulazio-denborak eta DE kopuruak mugatzen dute.

DEMaren formulazioak duen malgutasunak DEen arteko erlazioak neurrira definitzeko aukera ematen du. Harriaren DEM ereduak harriaren 
morfologia granularra eta portaera mekanikoa erreproduzitu behar ditu. Abiapuntua DE bat ale urratzaile batekin ordezkatzea da. Formulazio esplizituak DEak zurrunak eta haien arteko kontaktua leuna izatea dakar. Formulazioak hiru oinarri ditu: (a) DEen arteko erlazioak, (b) kontaktu detekzio-algoritmoa eta (c) integrazio-eskema. Aukeren arteko konbinaketak soluzio anitzak eskaintzen dituenez, arlo askotako fenomeno fisikoak modelatzeko gai da.

Elementuen arteko interakzioak (a) nahieran molda daitezke, kontaktuarekiko (elastikoa, Hertziarra...), loturarekiko (malgukia, habea) edo distantziarekiko menpeko (eremu elektromagnetikoa, bero-kondukzioa...) tratamendua emanez. Aglomeratzaileak ale urratzaileekin batera 3D egitura zurruna osatzen dute; bien konbinaketak RVE eskala gainditzean portaera jarraitua erakusten du [15]. Unitate minimoa ale-neurriak eta urratzaile frakzio bolumetrikoak definitzen dute. Aglomeratzaile-zubiaren akzioa habearenaren parekoa da. Habeen haustura-tentsioa definituz gero, pitzadura edota ale-askatzeen analisia ahalbidetuko luke (egiteke dagoen ataza).

DEMan erabiltzen diren habeak Euler-Bernoulli habe teorian oinarritzen dira [14]. Habe elastikoak bi geometria parametrok $\left(L_{\mu}\right.$ hasierako luzera eta $d_{\text {be }}$ diametroa) eta bi propietate mekanikok ( $E_{\mu}$ elastikotasun-modulua eta $v_{\mu}$ Poissonen modulua) definitzen dituzte. Habeek sekzio zirkularra dute; haien diametroa habeak lotzen dituen bi elementuen diametroen batez bestekoari $r_{\mu}$ murrizpen-faktorea biderkatuz definitzen da. DEen diametroen balioak aldakorrak direnez, zuzenean $r_{\mu}$ erabiltzen da habearen diametroa izendatzeko. $L_{\mu}$ habeak lotzen dituen elementuen arteko hasierako distantzia da. Iterazio bakoitzean DEen posizio- eta orientazio-aldaketak hasierakoekiko kalkulatzen dira. Bi elementuen arteko luzera- eta orientazio-aldaketa erlatiboek finkatzen dituzte haien arteko indarrak (axialak eta ebakitzaileak) eta momentuak (makurdura eta bihurdura). Hasieran, habeak kargarik gabe daude (4(a) Ir.) eta posizio hori hartzen da erreferentziatzat; 4(b) Irudiak habea kargatua erakusten du, bi elementuen arteko desplazamendu erlatiboaren ondorioz.

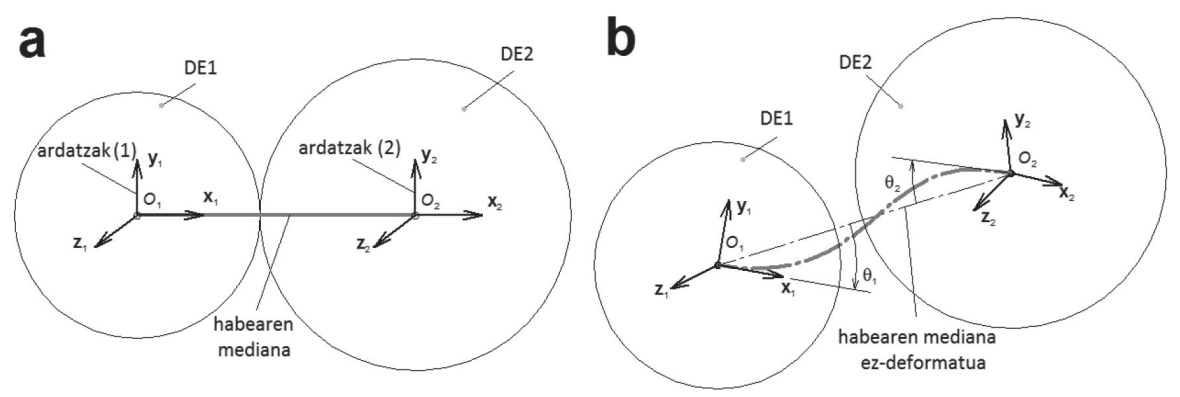

4. irudia. Habe elastikoa (a) atsedenean eta (b) kargatuta [14]. 
Harriaren egituraren zenbakizko eredua artezketan

Habeen erabilerak harria osatzen duten DEen arteko kontaktu-detekzio algoritmoaren (b) beharra ezeztatzen du, DEen arteko loturak ezagunak baitira. Integrazio-eskemak (c) iterazio bakoitzean zenbakizko integrazioa burutzen du, hurrengo iterazioan DE bakoitzak izango dituen posizio eta orientazio berriak kalkulatzeko. Tchamwa-Vielgosz eskema aukeratu da, konbergentzia hobetzeko eskemak zenbakizko moteltzea gehitzen baitio [16].

DE esferikoak erabili ohi ditu DEMak sinpletasunagatik, baina DE elipsoidalak, esfera-aniztunak eta poliedroak ere erabili izan dira beste aplikazioetan. Esferaren definizioa da sinpleena: ereduaren sorkuntza eta kontaktu-detekzioa errazten ditu. Aleen geometriak erlazio zuzena du trinkotzean eta, beraz, harriaren egituraren irekitasunean. Ale-geometria kubikoaren eta angeluarraren aspektu-erlazioak batetik hurbil daude; puntadunek, berriz, dimentsio bat beste biak baino luzeagoa dute. Lik [5], ale urratzaile amorfoak DE esfera-aniztunekin modelatzea proposatzen du, nahiz eta ideia aurrera ez eraman. Horren ordez, moztutako oktaedro elementua garatzen $\mathrm{du}$, esferoidearen eta oktaedroaren arteko intersekzio Boolearra. DEen artean kontakturik ez dago, eredua astinduz sortzen baitute. Beraz, Liren ereduan oktaedroen erabilera ez dago arrazoitua. Harrien fabrikazioan trinkotze-prozesua sinterizazio bidez simulatzeko, aldiz, bai, ale-geometriak garrantzia du. Geometria jakina duten urratzaileak (CBN, diamantea) tetraedro-oktaedro nahasketarekin modelatu daitezke; ale amorfo puntadunak simulatzeko, berriz, esfera bikoitz (edo esfera anitz) edota poliedro DEak. Bestalde, aluminazko harrietan diamantaketak gainazal-topografia eraldatzen du, baita DEM ereduan ere, eta, beraz, DE geometriak ez du garrantzirik topografia modelatzean.

Elementuen geometriak soilik ereduaren sorkuntzan eragina duenez, arrazoizkoa da urratzaileak DE esferikoez modelatzea ale kubikoentzat eta angeluarrentzat. Lan honetan DE esferikoak aukeratu dira, proba esperimentaletan erabilitako harriak ale angeluarrak baititu. Ale-geometria puntaduna (luzatua) modelatzeko, eredua DE esfera-bikoitzera eguneratu beharko litzateke.

\subsection{DEM ereduaren sorkuntza}

DEM eredua simulatu nahi den fenomeno fisikoarekiko eraiki behar da. Lehen aipatu bezala, Lik eta Osak proposatutako astinzea eta sinterizazioa doikuntzarekin, biek ez dituzte errealitatean sortzen diren aleen arteko kontaktuak eta lotura-kopuruak islatzen. Lan honek zenbakizko sinterizazioa erabiltzea proposatzen da, baina zuzenean $d_{\mathrm{g}}$ eta $V_{\mathrm{g}}$ kontsignatzat hartuta. André et al.en [14] prozedura moldatu da, berez eremu jarraituen ereduak sortzeko garatua (5 Ir.). 


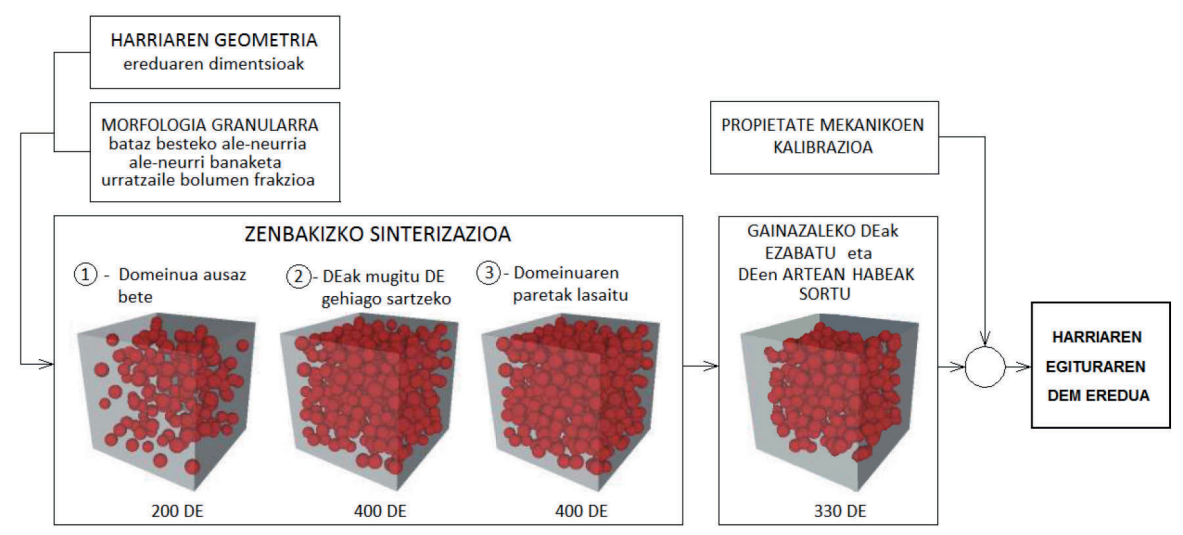

5. irudia. Harriaren DEM eredua eraikitzeko fluxu-diagrama zenbakizko sinterizazio bidez.

Erronka, harriaren ezaugarrietatik abiatuz, egituraren deskripzio morfologikoa eta mekanikoa lortzea da. Eredua eraikitzeko beharrezkoak diren parametroak, geometrikoak (harriaren morfologia granularra deskribatzeko: $d_{\mathrm{g}}, V_{\mathrm{g}}$ eta ale-neurriaren dispertsioa) eta propietate mekanikoak (elastikotasuna: $E_{\mathrm{s}}$ eta $v_{\mathrm{s}}$ ) dira.

Izendapenak zehazten ditu datu horiek. Ale-neurrien nahasketa ezagutuz gero, aleneurriak banaketa normala izango $d u\left(d_{\mathrm{g}}, \sigma_{\mathrm{g}}\right)$; ezezaguna bada, berriz, banaketa uniformea $\left(d_{\mathrm{g}}, \mu_{\mathrm{g}}\right)$. Urratzaile eta aglomeratzaile motaren eraginak graduak jasotzen ditu; beraz, ez dira sarrera-datuak DEM ereduan. Era berean, Lik ez bezala, aglomeratzaile eta porositate frakzio bolumetrikoak ez daude esplizituki modelatuak DEM ereduan, helburua harriaren egitura granularraren portaera mekanikoa simulatzea baita DE-habe sarea baliatuz. Ereduaren geometria eta dimentsioak ere erabaki behar dira DEM eredua eraikitzeko; lan honetan esfera eta zilindroa erabili dira.

Zenbakizko sinterizazioak DEM eredua domeinu itxia DEez ausaz betetzen du. Domeinu itxiak pareta elastikoak ditu. Lehenengo pausoan, ereduaren geometria duen domeinu itxia DEez betetzen da ausaz. DEek banaketa uniformea edo normala jarraitzen duen ausazko diametroa dute. Etapa, ausaz DE berria gehitzeko lekurik ez dagoenean bukatzen da. Bigarren etapa prozesu iteratiboa da, lehen pausoan ipinitako DEak birkokatzen dira, DE berriak gehitu ahal izateko. DEen artean elkarsartze txiki bat baimentzen da. Lekua gutxitzen den heinean, DEen energia zinetikoaren batura gutxituz doa. Energia zinetikoak aurrez ezarritako muga minimora iristean bukatzen da bigarren etapa. Hirugarren etapan zuzentzen dira DEen arteko elkarsartzeak, domeinuaren pareten zurruntasuna erlaxatuz. Behin harria- 
ren eredua sortuta, kalibrazio bidez doitutako propietate mekanikoak habeei transferitzen zaizkie.

1. taula. Sortutako ereduen sarrera parametroek eta $V_{\mathrm{g}}$ minimoen eta maximoen $N_{\text {DE }}$ eta $\mathrm{CN}$.

\begin{tabular}{|c|c|c|c|c|c|}
\hline $\begin{array}{l}\text { Ale-neurria, } \mathrm{M} \\
\text { Galbahe irekiera }(\mu \mathrm{m})\end{array}$ & \multicolumn{2}{|c|}{$\begin{array}{l}\# 36 \\
476\end{array}$} & $\begin{array}{l}\# 46 \\
354\end{array}$ & $\begin{array}{l}\# 60 \\
255\end{array}$ & $\begin{array}{l}\# 80 \\
178\end{array}$ \\
\hline \multirow[t]{2}{*}{ Bataz besteko ale-neurria, $d_{\mathrm{g}}(\mu \mathrm{m})$} & \multicolumn{2}{|c|}{415} & 323 & 233 & 165 \\
\hline & $\max$. & $\min$. & $\max . \min$. & $\max . \min$. & $\max . \min$. \\
\hline Urratzaile frakziobolumetrikoa, $V_{\mathrm{g}}(\%)$ & 50,1 & 63,3 & $51,6 \quad 62,4$ & $51,8 \quad 58,1$ & $52,8 \quad 58,2$ \\
\hline Elementu kopurua, $N_{\mathrm{DE}}$ & 696 & 864 & 1.5261 .840 & $4.078 \quad 4.549$ & 11.51412 .816 \\
\hline Koordinazio-zenbakia, CN (habe/DE) & 5,47 & 2,62 & $5,62 \quad 3,61$ & $5,52 \quad 2,87$ & $5,67 \quad 3,45$ \\
\hline
\end{tabular}

Eredua sortzeko sinterizazio prozedurak berezkoa du DEM ereduaren gainazalean DEen pilaketa efektua. Efektu hori zuzentzeko, ereduaren gainazaleko $3 \cdot d_{\mathrm{g}}$ lodiera duen DE geruza ezabatzen da. Hau da, DEM ereduaren erdiguneak bilatzen den $d_{\mathrm{g}}-V_{\mathrm{g}}$ morfologia granularra guztiz betetzen du: DEak kontaktuan daude eta DE bakoitzak dagokion habe kopurua (koordinazio-zenbakia edo coordination number, $\mathrm{CN}$ ) edo aglomeratzailezubiak ditu. 6 Irudiak Osaren eta lan honetan proposatutako ereduak alderatzen ditu: lehenengoan (6(a) Ir.), DEek beti habe-kopuru bera dute eta ez daude kontaktuan; bigarrengoan (6(b) Ir.), habe kopurua $V_{\mathrm{g}}$-ren funtzioan doitzen da eta DEak kontaktuan daude.

a

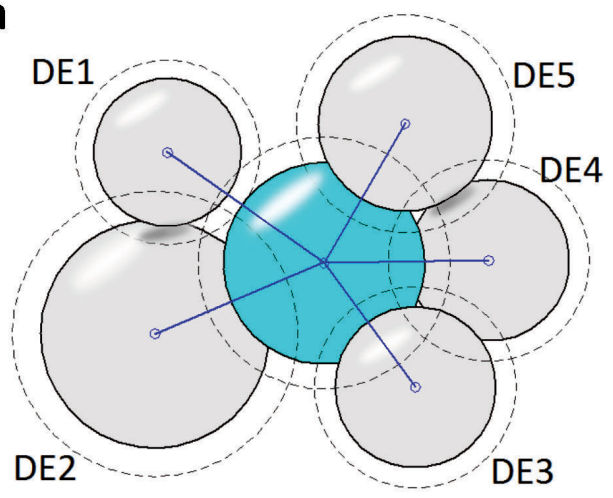

b

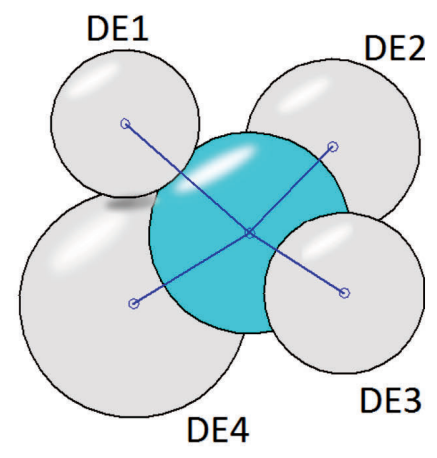

6. irudia. (a) Usaren ereduak sortzean $N_{\mathrm{DE}}$ da erreferentzia eta ondoren $d_{\mathrm{g}}$ doitzen da $V_{\mathrm{g}}$ lortzeko [6]; (b) proposatutako ereduak zuzenean $d_{\mathrm{g}}$ eta $V_{\mathrm{g}}$ dira erreferentzia sorreran eta DEak kontaktuan egotea lortzen da. 
Prozedura berriaren potentziala frogatu da hainbat eredu sortuz aleneurri bakarrarekin, hau da, nahasketarik gabe. Lau ale-neurri frogatu dira (\#36, \#46, \#60, \#80), guztietan geometria 4,8 $\mathrm{mm}$ diametroko esfera da. 7. Irudiak emaitza denak eta 1 Taulak balio minimoak eta maximoak erakusten dituzte. Ale-neurri handiek $V_{\mathrm{g}}$ handiagoak lortzen dituzte eta emaitzek hori islatzen dute. Habe-kopurua DEko $(\mathrm{CN})$ balioak handituz doaz, $V_{\mathrm{g}}$ handitzen den heinean eta DEak kontaktuan daude. Ereduaren sorkuntza ausazkoa denez, balioen dispertsioa ere kontuan hartu behar da.

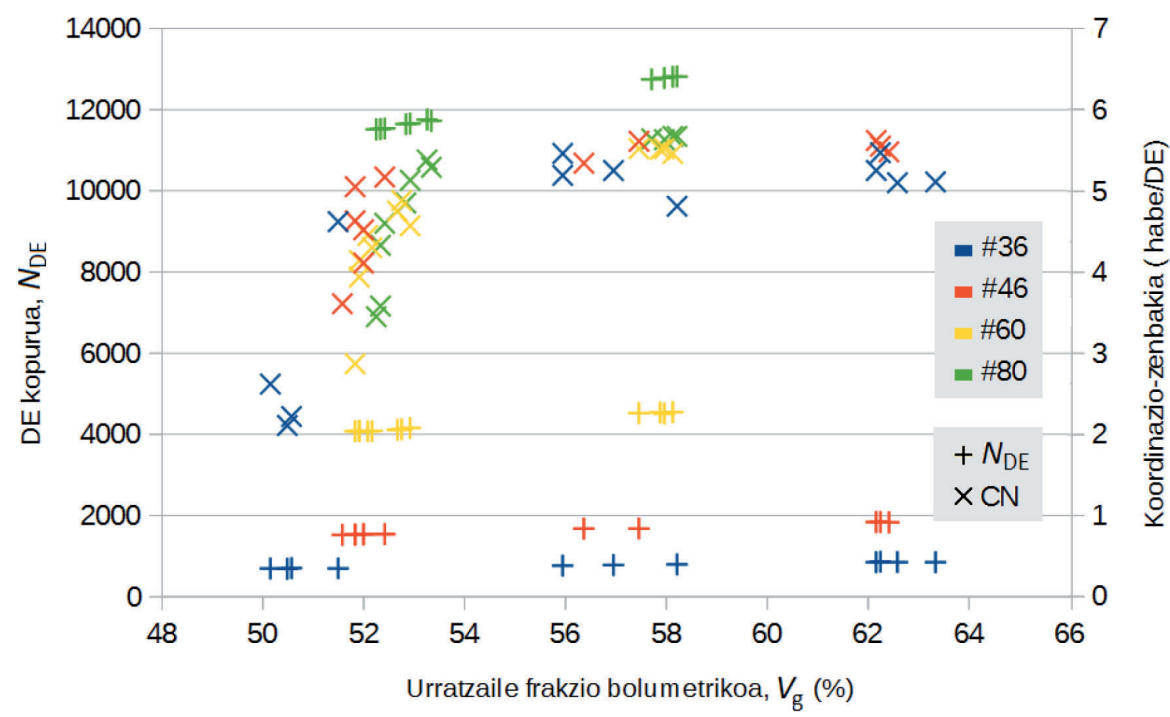

7. irudia. Lau ale-neurri nahastu gabe; banaketa uniformea eta domeinu-bolumen berdina; sortutako ereduen $N_{\mathrm{DE}}$ eta CN (habe/DE) $V_{\mathrm{g}}$-rekiko. da.

Horrela, atal honetan harriaren morfologia granularra modelatzea lortu

\subsection{Habeen propietate mekanikoen kalibrazioa: homogeneizazioa}

Elementu finituen metodoan ez bezala, solido jarraituen mekanikako legeak ezin dira DEM formulazioan zuzenean aplikatu. Urratzaileak eta aglomeratzaileak propietate mekaniko ezberdinak dituzte eta, gainera, harriaren gorputza porotsua da. Harriaren gorputzaren propietate mekanikoak, $E_{\mathrm{s}}$ elastikotasun-modulua eta $v_{\mathrm{s}}$ Poissonen modulua, DEM ereduan habeen propietateen ondorioz eskala makroskopikoan azaleratzen diren propietateak dira. Horrela, habeen propietate mekanikoek, eskala mikroskopikoan, modelizatutako materialaren portaera makromekanikoa definitzen dute. Fenomeno horri homogeneizazio deritzo [15]. 
Propietate mekanikoen neurketa esperimentalean bezala, zenbakizko trakzio-proben bidez kalibratzen dira habeen mikroeskalako propietateak. André et al.ek deskribatzen dute habeak kalibratzeko prozedura eremu jarraituak simulatzeko [14]. Kalibrazio-prozedura lan honetako harriaren DEM ereduaren morfologia granular heterogeneoari moldatu da. Zenbakizko trakzio-probetan lagin zilindrikoei mutur bat finkatu eta bestean indarra aplikatzen da. Simulazioak luzeratako eta alboko deformazioak monitorizatzen ditu, makroeskalan DEM laginak izan duen elastikotasun-modulua eta Poissonen modulua kalkulatu ahal izateko. Mikroeskalan habearen hiru parametro dira doitu beharrekoak $\left(v_{\mu}, r_{\mu}, E_{\mu}\right)$ materialaren makroeskalako bi propietateekiko $\left(E_{\mathrm{s}}, v_{\mathrm{s}}\right)$. Kalibrazioan, dimentsio berdineko sei eredu tamaina erabili dira $(500,1.000,2.000,5.000,10.000$ eta 20.000 DE). DEM eredu tamaina bakoitzerako lau lagin prestatu dira. DEM ereduaren sorkuntza ausazkoa denez, lau laginak ezberdinak dira eta emaitzak lau emaitzen batez bestekoak dira. Habeen propietateen kalibrazioaren fluxu-diagrama azaltzen du 8. Irudiak.

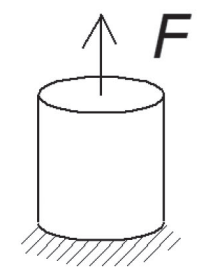

LAGINEN PRESTAKETA $\mathrm{N}_{\mathrm{DE}}=500,1000,2000$ $5000,10000,20000$ Bakoitzetik 4 lagin

ZENBAKIZKO TRAKZIO-FROGA

SARRERA-DATUAK
Harriaren propietate mekanikoak
$v_{\mathrm{s}}, E_{\mathrm{s}}$
EZEZAGUNAK
Habeen propietate mekanikoak
$v_{\mu}, r_{\mu}, E_{\mu}$

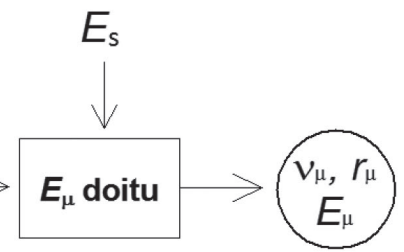

8. irudia. Habeen propietateen kalibratzeko prozeduraren fluxu-diagrama [14].

Habearen $E_{u}, r_{\mu}$ eta $v_{u}$ parametroek, bakoitzak bere eran eragiten dute materialaren $E_{\mathrm{s}}$ eta $v_{\mathrm{s}}$ makropropietateetan. Saiakuntzen diseinu (DOE) bidez faktore bakoitzaren eragina makropropietateetan aztertu da (9. Ir.):

$-v_{\mu}$-k makroeskalan $\left(E_{\mathrm{s}}, v_{\mathrm{s}}-\mathrm{k}\right)$ apenas du eraginik (9(a) Ir.).

$-r_{\mu}$-k eta $E_{\mu}$-k makroeskalako Youngen moduluan $\left(E_{\mathrm{s}}\right): r_{\mu}$ berdinarentzat $E_{u}$ handitzean $E_{\mathrm{s}}$ proportzionalki handitzen da (distantzia berdina da) eta $r_{\mu}$ handitzean $E_{\mathrm{s}}$ esponentzialki handitzen da (9(b) Ir.).

$-r_{\mu}$-k eta $E_{\mu}$-k makroeskalako Poissonen moduluan $\left(v_{\mathrm{s}}\right): E_{\mu}$ konstanteko lerroak gainjartzen dira eta $r_{\mu}$-rekiko joera beherakorra erakusten dute; $r_{\mu}$ berdinarentzat $E_{\mu}-\mathrm{k}$ ez du $v_{\mathrm{s}}$-n eragiten (9(c) Ir.). 

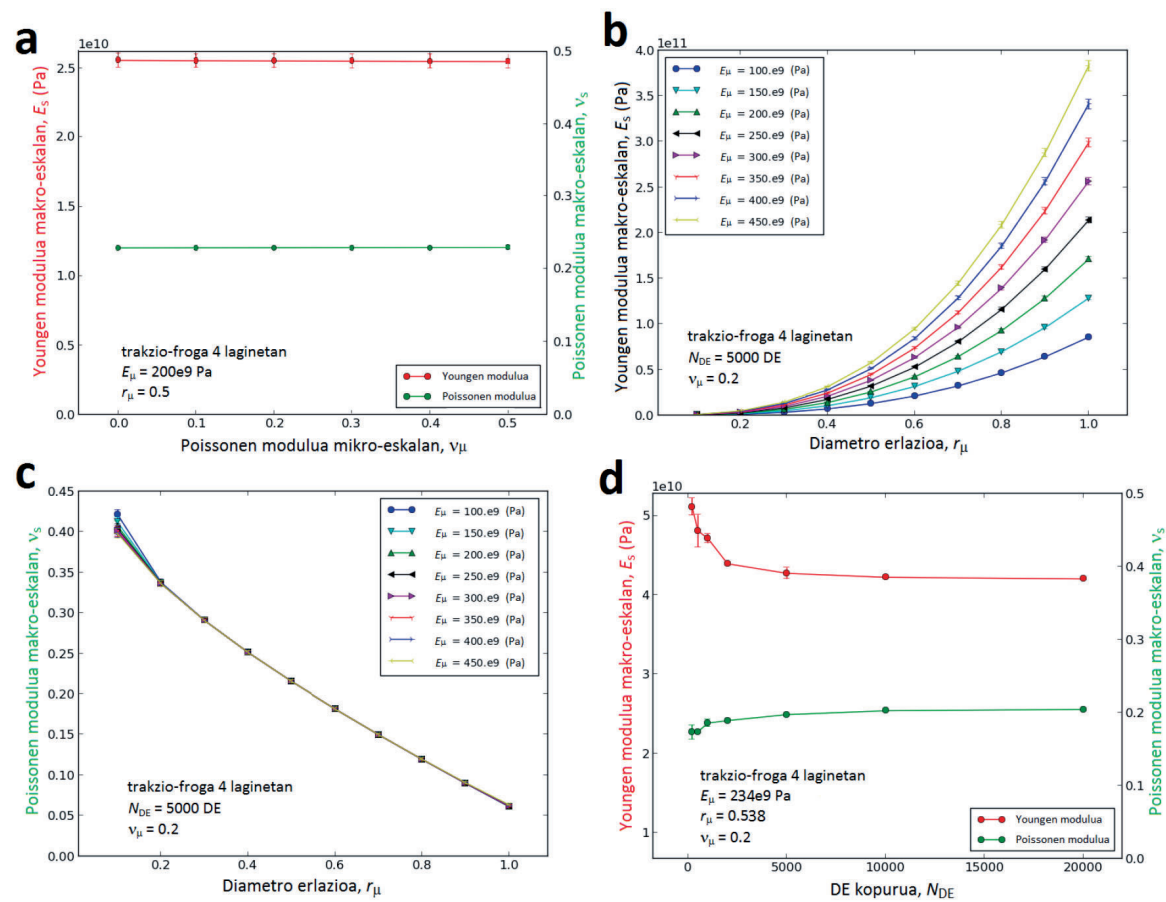

9. irudia. Habeen propietateen kalibrazioaren DUEa makroeskalako propietateekiko $\left(E_{\mathrm{s}}, v_{\mathrm{s}}\right)$ : (a) $v_{\mu}$; (b;c) $r_{\mu}$ eta $E_{\mu}$; eta (d) $E_{\mathrm{DE}}$ faktoreen funtzioan.

$-N_{\mathrm{DE}}$ DE kopuruaren eragina $r_{\mu}, E_{\mu}$ eta $v_{\mu}$ konstante mantenduz: neurri efektua nabarmena da $N_{\mathrm{DE}}$ txikietan eta handitzean balioak bat datoz (9(d) Ir.).

Ondorio horiek kontuan hartuta, kalibrazioa bi pausotan egiteko prozedura proposatu da. Lehen pausoan, $v_{\mu}$ habeen Poissonen moduluak makroeskalako propietateetan eraginik ez duenez, $v_{\mathrm{s}}$ harriaren Poissonen moduluarekin finkatzen da eta aldagai bat aurrezten da. Ondoren, $E_{\mu}$ finko mantenduz, $r_{\mu}$ habeen erradioa doitzen da harriaren $v_{\mathrm{s}}$-rekiko (10(a) Ir.). $r_{\mu}$ finko dela, $E_{\mu}$ aldatzeak eragin mespretxagarria dauka $v_{\mathrm{s}}-\mathrm{n}$ (9(c) Ir.). Bigarren pausoan, $v_{\mu}$ eta $r_{\mu}$ finkatuta, habearen $E_{\mu}$ elastikotasun-modulua doitzen da materialaren harrien $E_{\mathrm{s}}$ elastikotasun-modulua erabilera tarterako (10(b) Ir.). 3 ekuazioak 10(b) Irudiko grafikoko $E_{\mu}$ eta $E_{\mathrm{s}}$ arteko erregresiofuntzioa erakusten du. Horrela, habeei $E_{\mu}, r_{\mu}$ eta $v_{\mu}$ balioak ezarriz gero, materialak $E_{\mathrm{s}}$ eta $\nu_{\mathrm{s}}$ propietateak erakusten ditu makroeskalan.

Mikroeskalako propietateak ereduaren dimentsioekiko edo urratzaile frakzioarekiko independenteak dira, hau da, graduaren arabera soilik aplikatzen dira. Propietate horiek DEM eredua eraiki ondoren eta simulazioa 
a

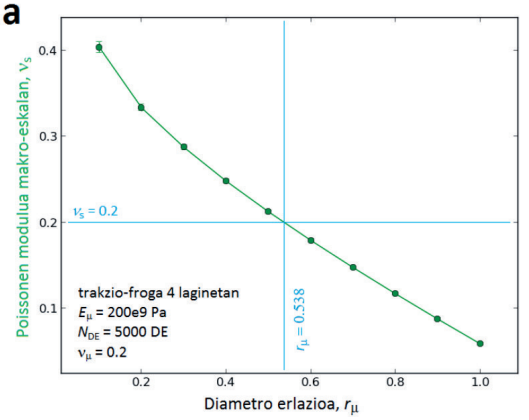

b

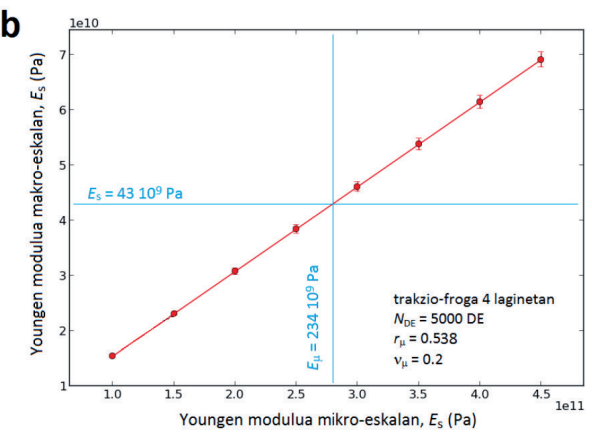

10. irudia. Habeen propietateen kalibrazioa: $v_{\mu}\left(=v_{\mathrm{s}}\right.$ ) finkatu ondoren; (a) $r_{\mu}$ zehazten da $v_{\mathrm{s}}$-rekiko doituz; ondoren; (b) $E_{\mu}-\mathrm{k} E_{\mathrm{s}}-\mathrm{n}$ duen eragina aztertzen da $v_{\mu}$ eta $r_{\mu}$ konstante mantenduz.

hasi aurretik aplikatzen dira. Hala ere, habe kopurua DEko aldatu egiten da $V_{\mathrm{g}}$ urratzaile frakzioarekiko. Horren eragina txikia da baina aztertzeke geratzen da.

$$
E_{\mu}=5,3908 E_{\mathrm{s}}+2,4873 \quad\left(R^{2}=0,9994\right)
$$

\section{ONDORIOAK}

Lan honetan artezketan erabiltzen den harriaren zenbakizko eredua aurkeztu da. Harriaren materiala heterogeneoa eta ez-jarraitua da, konglomeratu granular porotsua. DEMa ongi moldatzen da material konposatuen karakterizazioetara. DE batek ale urratzailea modelatzen du eta habe batek, berriz, elkarren alboan dauden bi aleen arteko aglomeratzaile-zubia; DE eta habe guztien multzoak harriaren 3D egitura sortzen du.

Helburua gaur egungo harriaren DEM ereduen aleen arteko kontaktu eza konpontzea izan da, errealitatean bezala. Horretarako, zenbakizko sinterizario prozedura moldatu da, zuzenean ale-neurria eta urratzaile frakzioa erreferentziatzat hartuz. Helburuak bete dira: harriaren ezaugarrietatik abiatuz, morfologia granularra modelatzen duen zenbakizko eredua lortu da. Erabili ditugun DE esferikoak egokiak dira ale-geometria angeluarrarentzat eta kubikoarentzat, baina ez puntadunentzat duten aspektu-erlazio handiagatik.

Eredua eraiki ondoren habeen propietate mekanikoak ezartzen dira. Habe multzoaren portaera habe bakoitzaren ekarpenaren funtzioan dago, 
eta multzoaren propietate mekanikoak dira guk makroeskalan behatzen ditugunak. Propietate mekanikoen kalibrazio prozedura moldatu da, harriaren ezaugarri berezietara egokituz. Kalibrazioa gradu eremu guztiarentzat egin da. Azterketa are gehiago findu daiteke, egitura-zenbakia ere kontuan hartuz.

Aurkeztu den harriaren DEM ereduak aplikazio interesgarriak ditu. Agerikoena da konposizioaren funtzioan harriaren morfologia granularra eta propietate mekanikoak aurreikustea. Aleko aglomeratzaile-zubi kopuruak habe kopuruarekin bat egiten duenez, ale-askatze diamantaketa- eta higadura-mekanismoak azter daitezke. Eta gainazala moldatuz, diamantaketak sortutako topografia inplementatu dezakegu, indarrak, kontaktu-eremua eta piezan lortutako gainazal zimurtasuna aurreikusteko ereduak garatzeko.

Aurkeztu den eredua aukera asko irekitzen dituen hasiera-puntua da.

\section{ESKERTZAK}

Egileek UPV/EHU-ko SGIkerren laguntza teknikoa, giza babesa eta Europako finantziazioa (FEDER eta FSE) eskertzen dituzte. DEM simulazio GranOO software librearekin eraman da aurrera, www.granoo.org-en banatua eta GranOO taldearen laguntzarekin.

\section{BIBLIOGRAFIA}

[1] KLOCKE F., BECK T., HOPPE S., KRIEG T., MULLER N., NOETHE T., RAEDT H. eta SVEENEY K. 2002. «Examples of FEM application in manufacturing technology». Journal of Materials Processing Technology, 120, 450-457.

[2] BRINKSMEIER E., AURICH J., GOVEKAR E., HEINZEL C., HOFFMEISTER H., KLOCKE F., PETERS J., RENTSCH R., STEPHENSON D., UHLMANN E. 2006. «Advances in modeling and simulation of grinding processes». CIRP Annals-Manufacturing Technology, 55, 667-696.

[3] DOMAN D., VARKENTIN A. eta BAUER R. 2009. «Finite element modeling approaches in grinding». International journal of machine tools and manufacture, 49, 109-116.

[4] LI H., YU T., ZHU L. eta VANG V. 2015. «Analysis of loads on grinding wheel binder in grinding process: insights from discontinuum-hypothesisbased grinding simulation». International Journal of Advanced Manufacturing Technology, 78, 1943-196.

[5] LI H., YU T., ZHU L. eta VANG V. 2015. «Modeling and simulation of grinding wheel by discrete element method and experimental validation». International Journal of Advanced Manufacturing Technology, 78, 1-18. 
[6] OSA J.L., SANCHEZ J.A., ORTEGA N., IORDANOFF I. eta CHARLES J.L. 2016.«Discrete-element modelling of the grinding contact length combining the wheel-body structure and the surface-topography models». International Journal of Machine Tools and Manufacture, 110, 43-54

[7] KLOCKE F. 2009. «Manufacturing Processes 2. Grinding, Honing, Lapping». Springer-Verlag RVTH edition, Berlin.

[8] MALKIN S. 2008. «Grinding technology». Industrial Press, New York.

[9] DECNEUT A., PETERS J. eta SNOEYS R. 1970. «Sonic testing of grinding wheels». Centre de Recherches Scientifiques et Techniques de l'Industrie des Fabrications Mc-talliques, Bordeaux.

[10] ZHANG J., GUAN P., SU C., YU T. eta VANG V. 2011. «Simulation of grinding wheel with random three-dimensional abrasive and microporous bond». Key Engineering Materials, 487, 209-214

[11] BRAKHAGE K., MAKOVSKI M., KLOCKE F. eta WEISS M. 2011. «Grinding Vheel Modeling. Development of a mathematical Model». MASCOT11-IMACS/ISGG Workshop, Rome.

[12] KLOCKE F., BARTH S., VROBEL C., WEISS M., MATTFELD P., BRAKHAGE K. eta ROM M. 2016. «Modelling of the Grinding Vheel Structure Depending on the Volumetric Composition». Procedia CIRP, 46, 276-280.

[13] DOMAN D., VARKENTIN A. eta BAUER R. 2006. «A survey of recent grinding wheel topography models». International Journal of Machine Tools and Manufacture, 46, 343-352.

[14] ANDRE D., IORDANOFF I., CHARLES J. eta NEAUPORT J. 2012. «Discrete element method to simulate continuous material by using the cohesive beam model». Computer Methods in Applied Mechanics and Engineering, 213, 113-125.

[15] CAMBOU B., JEAN M. eta RADJAI F. 2013. «Micromechanics of granular materials». John Viley eta Sons, New York.

[16] JEBAHI M., DAU F., CHARLES J. eta IORDANOFF I. 2016. «Multiscale modeling of complex dynamic problems: an overview and recent developments». Archives of Computational Methods in Engineering, 23, 101-138. 